\title{
Primary Closure of Maxillo-Facial Wounds
}

\author{
Major T Gibson, \\ $M B, C h B, F R C S(E d)$, RAMC \\ From a Maxillo-Facial Surgical Unit, BLA
}

\begin{abstract}
FOREWORD: This paper was written during the BLA campaign in Northern Europe in 1944/45. Much of it was written in tents and I carried out most of the photography myself. It was submitted to the Editor of the British Journal of Surgery in 1945 who accepted it for publication. A year or two later, having heard nothing more, I wrote to the Editor who told me that my paper with others on maxillo-facial topics had been sent to Professor T Pomfret Kilner for editing and arranging. Kilner did nothing about this project and 10 years later in 1955, the paper was returned to me with a note from the Editor to say that there was no longer much interest in this subject and perhaps it should wait until just before the next war! For 30 years it has lain in my desk until Air Commodore Ronald Brown, writing a history of plastic surgery in the RAF, heard of it and I sent it to him. With the help of Mr Antony F Wallace, the Archivist of the British Association of Plastic Surgeons, it was sent to Brigadier P Abraham and has now reached home.
\end{abstract}

SUMMARY: In maxillo-facial wounds with soft tissue involvement, the most important object in the initial treatment is to secure primary closure without deformity, or, if that is not possible, primary epithelialisation of the raw surfaces. In addition to the early healing with minimal scar tissue which results, this allows further operative procedures to be carried out much earlier and under much simpler conditions than if healing had occurred by granulation and scarring.

The operative technique adopted in a series of 304 patients in a maxillo-facial surgical unit in the BLA included meticulous toilet and excision of wound surfaces before closure by several different methods: when soft tissue loss was minimal, direct closure in layers was effected; when the soft tissue defect was too large for direct closure the wound was closed by either local flaps or skin to mucous membrane suture or skin grafting of the raw surface. Examples of these methods are shown.

In a series of 165 cases in whom the immediate results have been personally observed or on whom reports have been received, 153 cases ( 93 per cent) have been completely successful, 10 cases ( 6 per cent) have had a partial breakdown of the wound, and two cases ( 1.2 per cent) have been complete failures.

Maxillo-facial surgery in World War $\mathrm{I}^{1}$, and in the first years of the present conflict ${ }^{2}$, has dealt almost exclusively with the late closure of facial wounds and with the secondary repair of deformities resulting from healing by scar tissue. Primary closure has rarely been attempted for several reasons. There was the delay which inevitably elapsed between the time of wounding and arrival at a maxillo-facial centre. Oldfield states that patients in the Desert Campaign were first seen usually 5 - 10 days after injury, most of the wounds being then septic. In addition, the experience of practically all war surgeons has bred a general fear of primary suture of any gunshot wound, no matter how tempting such a procedure might be. Indeed, it has become almost an axiom in this war that no wound shall be sutured primarily unless for very special reasons and then only if the patient can be kept under observation.

On the other hand, it must be remembered that the soft tissue coverings of the face differ radically from those elsewhere. They have a much greater blood supply. They are also uniquely splinted and kept at rest by the underlying bony framework. These factors alone make them particularly resistant to infection and the rapidity with which healing may occur is widely recognised. It should therefore be possible, if cases are seen early enough, to achieve direct primary closure of many facial wounds without fear of wound sepsis.
The present campaign with the BLA has provided unique opportunity to put this into practice. It has been the policy to keep the Maxillo-Facial Surgical Units as far forward as was consistent with the tactical situation. Maxillo-facial cases have therefore been seen, on an average, 12-36 hours after injury. There have been, of course, delays for various reasons, and some cases did not arrive until two, three or more days had elapsed, but this was unusual.

In addition this has been the first major campaign in which adequate supplies of penicillin have been available for practically every case.

In the early days of the campaign primary closure of facial wounds was tried tentatively and with some misgivings. A selected number of cases was kept under observation and it soon became apparent that, provided adequate wound toilet had been carried out, healing by first intention could be achieved in practically every case. Since then the ideal of treatment aimed at has been to obtain complete primary repair, or at least complete primary epithelialisation, in all soft tissue injuries of the face.

The advantages gained in attaining this ideal are several. Complete healing is achieved within a week, and the patient is spared the pain and toxaemia of a septic wound and the discomfort of repeated dressings. The greatest advantage of all, however, is the minimum 
amount of scar tissue which results. Further operative procedures, such as bone grafting, can be undertaken at a much earlier date, and under much easier conditions, than when healing has occurred by granulation tissue.

The purpose of this paper is to show that with proper care and technique, primary suture of gunshot injuries of the face can be an eminently successful procedure even when such wounds are grossly lacerated, contused and contaminated; that while it is not always possible for various reasons to achieve complete primary repair, much can be done as regards partial or complete primary epithelialisation of the raw surfaces.

The term "primary closure" throughout the text means closure at the first definitive operation. It does not imply any arbitrary time after injury but this has almost always been within the first four days.

\section{Material}

This paper is based on a study of 304 patients in whom primary suture of facial wounds was carried out and who were dealt with personally in a Maxillo-Facial Surgical Unit in the BLA. The wounds were of all varieties and all degrees of severity, from minor lacerations to extensive loss of part of the face. All were contaminated to some extent, many grossly so.

The patients arrived at a varying time after injury; many within a few hours. The majority however were first seen 12-36 hours later. Some were not received until three or more days had elapsed.

Their previous treatment had usually been confined to control of haemorrhage and resuscitation, with the local application of sulphonamide powder and a dressing. Many had the original shell dressing still in place. A few cases had been roughly sutured to retain large flaps in position, but in no case had complete wound toilet or definitive suturing been carried out.

Many had associated injuries: 60 per cent had associated fractures of the facial bones; 25 per cent had injuries involving the trunk and limbs. Cases with mandibular fractures often arrived with an impaired airway, suffering from the effects of a long period of partial anoxia. The general condition of the patients therefore varied enormously. While most had been adequately resuscitated in forward areas, many were in need of further transfusions of blood and plasma, and careful attention to the airway, before operation could be contemplated.

Following operation, the patients were held for a varying time. During rush periods, when large numbers of cases had to be dealt with in a short time, it was essential to evacuate cases as soon as they were fit to travel, unless they could be reasonably expected to be fit to return to duty within a week. This meant that a large number of the cases had to be evacuated on the second or third day after operation. When possible, however, an attempt was made to retain the more serious cases for 4-5 days, until some or all of the sutures had been removed. During the quieter intervals, it was possible to retain cases for a longer period, in some instances up t㫨 a few weeks.

Operating facilities varied from the operating tent tळ a fully equipped theatre in a modern hospital. The standard of work done, however, and the resulto achieved, appear to have been in no way affected by the? conditions under which treatment was carried out.

The patients were evacuated to maxillo-facial centres in the UK. Cards were sent with them asking for follow up reports. Few were returned but a certain amount o톨 feedback was achieved; it was always helpful and mostl㧀 favourable and encouraging.

\section{Methods and Techniques}

\section{General Considerations}

Resuscitation. Adequate surgical toilet and repair facial wounds is always time-consuming and cannot be hurried if success is to be achieved. A very extensive casద్ may often require 3-4 hours of operating time. It wa⿱亠े therefore necessary to postpone operation in all severe cases until it was felt that the maximum possible benefin had been derived from resuscitation measures.

Blood loss at operation, often required further blood transfusions during operation and postoperative $\mathbb{R}_{\text {? }}$ ? There is no doubt that, but for the never failing suppl blood and plasma in this campaign, much of this w would have been impossible.

General Chemotherapy. All cases of extensive wougdo were given a course of penicillin and one of ghe sulphonamide drugs, usually sulphathiazole. Penici was administered intramuscularly in a dosage of 12 , 田嘼 to 20,000 units every three hours. The course lasted five days as a rule, during which time the patient received $\mathbb{8}$ total dosage of 500,000 to 800,000 units. In a few cases continuous intramuscular drip was given, 100,000 unit? being injected every 24 hours.

Local Chemotherapy. Various powders were insufflate into the wounds in roughly half of the cases. They wer severally, sulphanilamide, sulphathiazole, marfanil and sulphathiazole and penicillin mixture $(5,000$ units pef $\mathrm{gm})$. Their value was very doubtful. Absolut haemostasis in any wound of the face is very difficult th secure until the sutures are inserted. It was a commoio sight, therefore, to see the "magic powder", which ha of course been insufflated before suturing was begun@ being washed out of the wound while suturing was i⿱乛龰 progress.

In cases in which a large cavity remained after suture or in which debridement could neither be achieved nos assured, a more useful method of administering loca penicillin was to insert a small bore rubber tube into the wound cavity before closure and drain the cavity wit soft rubber at the most dependent point. Through thi tube a varying amount of penicillin, 1,000 to 5,000 unitsog was injected three hourly for 3-5 days. 
No attempt was made, or indeed was possible, to correlate the use of the various drugs with the bacteriology of the wound. Chemotherapy was simply given prophylactically and in standard courses to all but the most minor cases.

Anaesthesia. Nitrous oxide and oxygen with small amounts of ether, or cyclopropane and oxygen, administered via an endotracheal tube from a closed circuit apparatus were used in practically all cases. Primary induction was by intravenous Pentothal or intravenous Avertin. Local anaesthesia was not used.

From the illustrations it will be appreciated that a large number of the cases presented many anaesthetic problems. The highest praise is due to the anaesthetists of the unit for the skill with which they surmounted all difficulties in these and similar cases.

\section{At Operation}

Associated Bony Damage. It is not proposed to deal in any detail with the treatment of the fractures of the facial bones associated with many of the soft tissue injuries. It cannot be too strongly emphasised, however, that their treatment, particularly in fractures of the jaws, is, in most cases, of more immediate importance than the treatment of the soft tissues. In general terms, treatment consisted in the removal of all grossly displaced and nonviable pieces of bone and teeth, followed by reduction and fixation of the fragments remaining. As a rule, the bony injuries were dealt with first in co-operation with a dental surgeon, before soft tissue treatment was commenced. There is no doubt that adequate fixation of the facial fractures contributed greatly to the healing of the soft tissue wounds.

Wound Toilet. It is difficult to convey the degree of contamination which existed in many of the cases. Every variety of foreign matter was found. The commonest was soil, but sand, gravel, oil and tar were frequent contaminants. Pieces of clothing or of helmet strap were often imbedded in the tissues. In wounds caused by land mines and booby traps it was usual to find foreign matter blown into every crevice of the wound and peppered into the surrounding skin. Sections of tissue from such wounds often showed, naked eye, minute particles driven to a depth of 2 to $3 \mathrm{~mm}$.

It was therefore of prime importance that the most thorough and careful wound toilet should be carried out before any attempt at wound closure was made.

Cetavlon 1 per cent was used for cleansing the skin and wound and proved efficient in removing most surface contaminants. Where tiny particles of debris were imbedded in the dermis, time spent in getting rid of as many as possible was worthwhile. The minute tracks, made by each little particle, seal over with amazing rapidity and, after 24 hours, it becomes increasingly difficult to remove them. Scrubbing with a hard nail brush was found to be the most efficient method. It was essential that they be removed as early as possible. If allowed to remain in the tissues a permanently disfiguring tattooing effect results.

Foreign Bodies. All accessible foreign bodies, all loose splinters of bone and all fragments of teeth were removed as far as possible. In certain cases, where a missile had become lodged in a relatively inaccessible part of the face, it was judged wiser to leave it in situ, than to undertake an extensive exploratory operation. No immediate ill results followed this practice. Whether such retained foreign bodies were the cause of any later trouble is not known.

Wound Excision. It has for long been taught and is still being taught that facial wounds should never be excised $^{2,3}$.

While this is true for some of the clean-cut incised wounds of civilian practice, it certainly does not hold good for the great majority of gunshot wounds. In most cases, the surfaces of such wounds and the skin edges are irregular, contused, often partly or wholly necrotic and, in many of the later cases, covered with sloughs. Wounds over which saliva has dribbled become rapidlyo coated with a grey-green necrotic film. In addition, many of the raw surfaces are actually ingrained with dirt which cannot be cleaned out. If complete closure of such wounds is to be obtained, complete excision of the wound is a sine qua non. If excision of a wound is incomplete, if contused, damaged or necrotic tissue is retained, then either the wound breaks down or an ugly scar results, requiring later excision and resuture. If adequate excision is carried out at the original operation, later scar excisions are often unnecessary.

At the same time, it must always be remembered that every millimetre of facial tissue is of inestimable value either in preventing deformity or, if deformity persists, in the later repair. Excision must be kept to the minimum necessary to effect two criteria: first, that all visibly damaged and contaminated tissue is removed; second, that the skin edges to be sutured present a clean "square-cut" appearance. A ragged torn edge is difficult to suture accurately, is liable to break down later, and if it does succeed, results in an unsightly scar line.

Skin flaps, with a narrow pedicle and a precarious blood supply, must be handled and trimmed with the greatest care to conserve the remaining blood vessels.

It was found most satisfactory to carry out excision of a wound according to a definite plan, the wound being divided into sections and each section being excised and haemostasis secured before proceeding to the next. Commencing in the depths of the wound, and working from within outwards, allowed the deeper parts to be dealt with before they were obscured by bleeding from the more superficial tissues. Haemostasis was secured primarily with haemostats, the larger vessels being 
ligated with the finest catgut. Diathermy was unfortunately not available. It might have proven of great value.

The greatest care was always taken to preserve intact important deep structures such as the parotid duct or branches of the facial nerve.

In certain cases, of course, anything approaching a complete debridement of the wound was out of the question. For instance, in wounds penetrating deeply through the ascending ramus of the mandible into the pterygoid fossa, or in through-and-through wounds just below the base of the skull and traversing the ethmoids, the deeper reaches of the track were too inaccessible. The policy in regard to such wounds was either to leave them widely open, or else to trim as much of the wound track as possible, close the skin and subcutaneous layers, and ensure adequate drainage of the remaining cavity. It was particularly in the latter type of case that repeated injection of the cavity with penicillin through a small bore indwelling tube was found of real value.

In extensive lacerations of the cheek and floor of the mouth, where access to the mucous membrane and depths of the wound through the mouth was cramped and difficult, no hesitation was felt in dividing the remainder of the cheek, horizontally at the angle of the mouth, in order to give adequate closure (eg. Case 1). Except for such cases, however, it was seldom necessary to make fresh incisions in order to effect complete wound toilet. Small, deep puncture wounds, such as the entrance wound of a rifle or machine gun bullet, were as a rule ignored. They healed rapidly without sepsis and with a small, hardly visible scar.

Wound Suture. When haemostasis had been achieved as far as possible, the wound was sutured from within outwards. In the early stages of the campaign, simple interrupted catgut sutures were used for closing mucous membrane, but the results were not satisfactory and breakdown of the wound was a common occurrence. There appeared to be two factors involved. Firstly, the catgut sutures often became undone very rapidly after operation. This may have been due to the effects of saliva, but was most probably due to faulty technique, the difficulty of tying a reliable knot with catgut in the depths of the oral cavity being very real in the prevailing circumstances. Secondly, the mucous membrane of the mouth is a very thin layer, rather loosely attached in places to the underlying tissues, and it is consequently very difficult to prevent inversion of the edges when simple sutures are used.

For these reasons, mucous membrane in all the later cases was closed with end-on matttress sutures of fine black silk, in order to obtain proper eversion of the edges. Breakdown rarely occurred after this procedure and the results were excellent. It has sometimes proved difficult to remove the more deeply placed sutures, but no harm has arisen from their presence, where they have been inadvertently retained up to two weeks after insertion. In all cases, an attempt was made to remove them about the 6 th day after operation.

The cut ends of muscle were coapted by fine interrupted catgut sutures.

In order to prevent later depression of the scar line, i응 is most important to bring the subcutaneous tissues? together before inserting the skin sutures. Interrupted fine catgut sutures on an atraumatic needle were used.

Black silk was used for suturing skin. Two grades were: used: a very fine silk which was employed in more delicate work such as wounds of the eyelids, nostrils or lips, and a medium grade which was generally used. The greatest care was always taken to try to coapt two rawes surfaces rather than two edges, and thus produce a flat $\overrightarrow{0}$ even scar line, neither everted nor inverted.

In a few cases, in which very regular wound marginsw were obtained, the wound was closed by a subcuticulas stitch of silk. Very few cases, however, lent themselves to this technique.

Wound Drainage. The most important single factor iñ causing breakdown of facial suture lines is haematom formation with later infection of the haematoma. It if almost impossible, because of its great vascularity, to secure absolute haemostasis in any extensive facpat wound without burying a very large amount of catgut any wound, therefore, in which a potential cavity present after suture, drainage was provided by mean@ soft corrugated rubber. Drains were removed after용 hours unless there was any indication to the contrary $\varnothing$

The site of drainage was either through the mesie dependent corner of the wound (remembering that i⿱ patient lying supine, the most dependent point?고옹 posterior rather than inferior), or by a separate smale stab incision in the submandibular region. A few speciao cases were drained into the mouth, but this was not ofte․․․ done because of the risk of infection.

Wound Dressing. In order further to preven haematoma formation, a pressure dressing was mos valuable. The routine dressing used was a layer of Tulle. Gras over the suture line, a pressure pad of dry gauz and cotton wool, the whole held in place by a creps bandage, reinforced if necessary by Elastoplast.

Post-Operative Care. In wounds in the neighbourhoog of the mouth, which were in constant contact with saliv and food debris, repeated dressings were carried oug three or four times a day. A high standard of mout hygiene was set (such cases usually had concomitan£ fractures of the mandible), and the mouth was kep $\bar{b}$ scrupulously clean by repeated irrigation after mealso The wound itself was swabbed dry and cleaned of a debris, dusted with sulphonamide powder, and dresse $\$$ with Tulle Gras. There is no doubt that the great carN which Ward Sisters have taken with the post-operative dressings has contributed greatly to the succese achieved. 


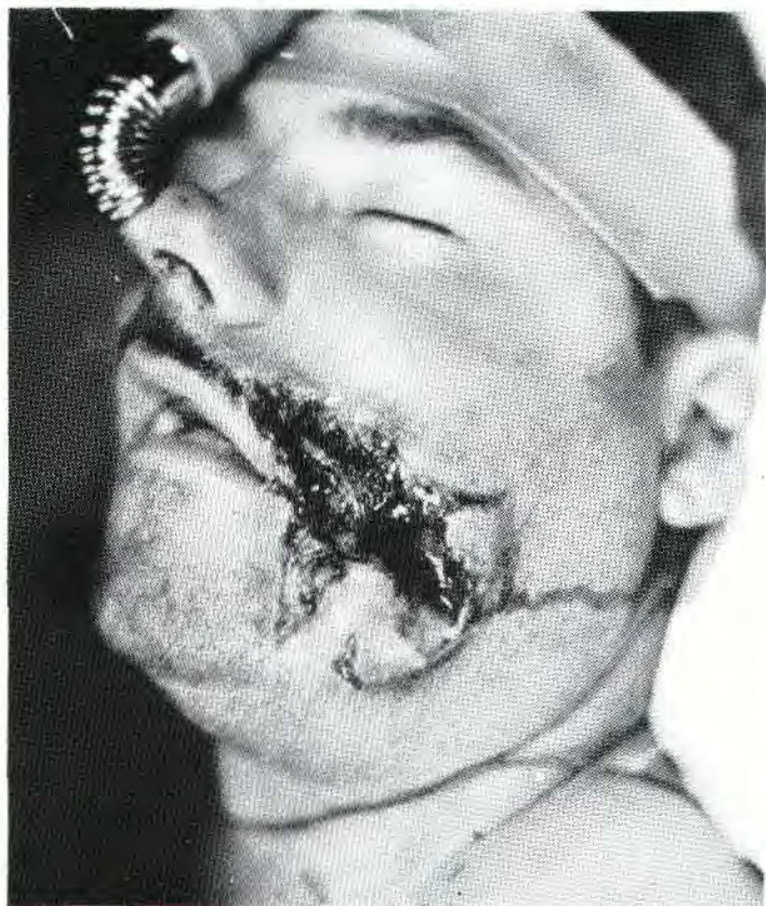

Fig.1A Case 1. Two days after wounding by a shell splinter.

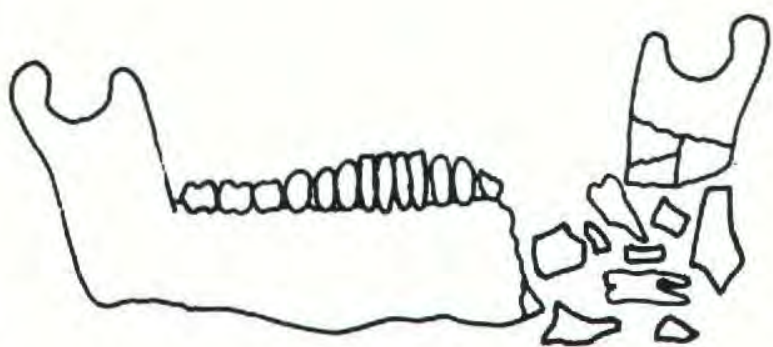

Fig.1C Case 1. The damage to the mandible fragments of which had been driven into all parts of the wound.

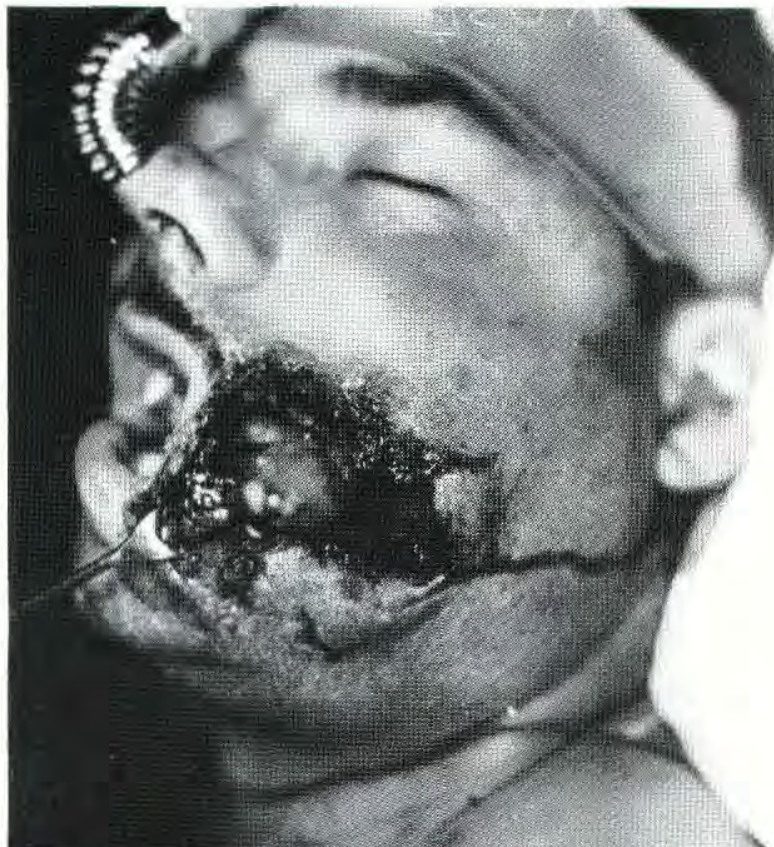

Fig.1B Case 1. The extensive tear in the buccal mucosa There was also a gash in the tongue.

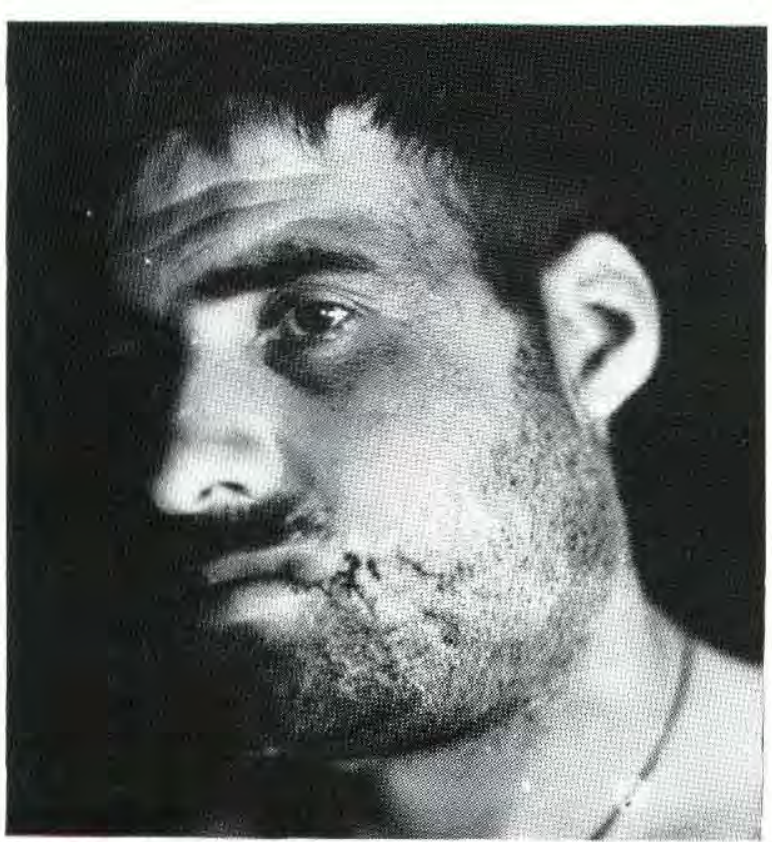

Fig.1D Case 1. On the fourth postoperative day after most of the sutures had been removed. The angle of the mouth had been divided to obtain access and the stitches there were left to the next day. 


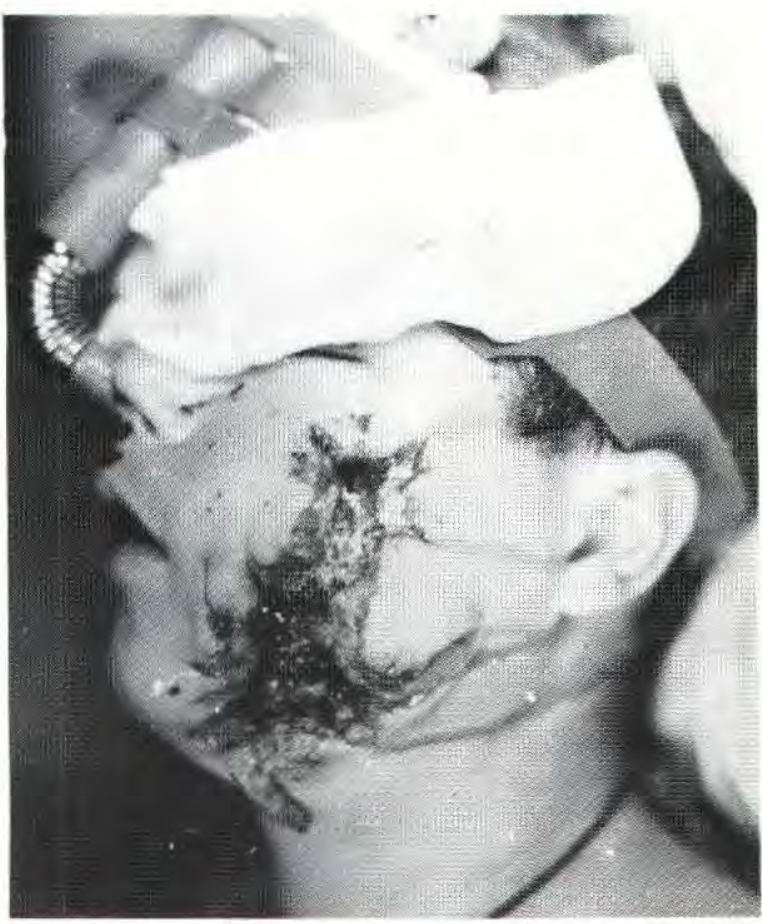

Fig.2A Case 2. Mortar wound at operation after two days. Note the many peripheral lacerations which must be excised and sutured before the main defect can be visualised.

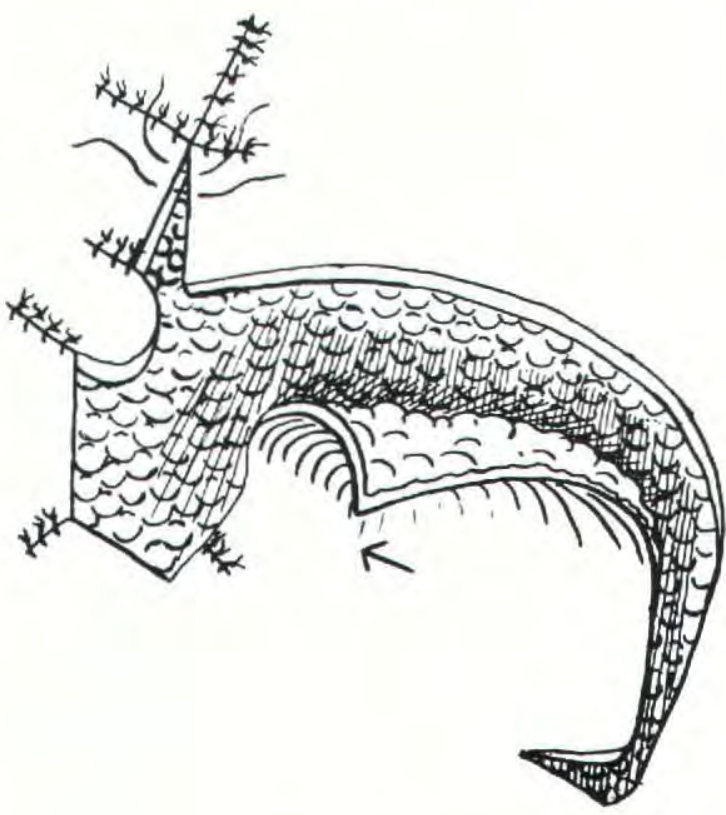

Fig.2C Case 2, Rotating the flap.

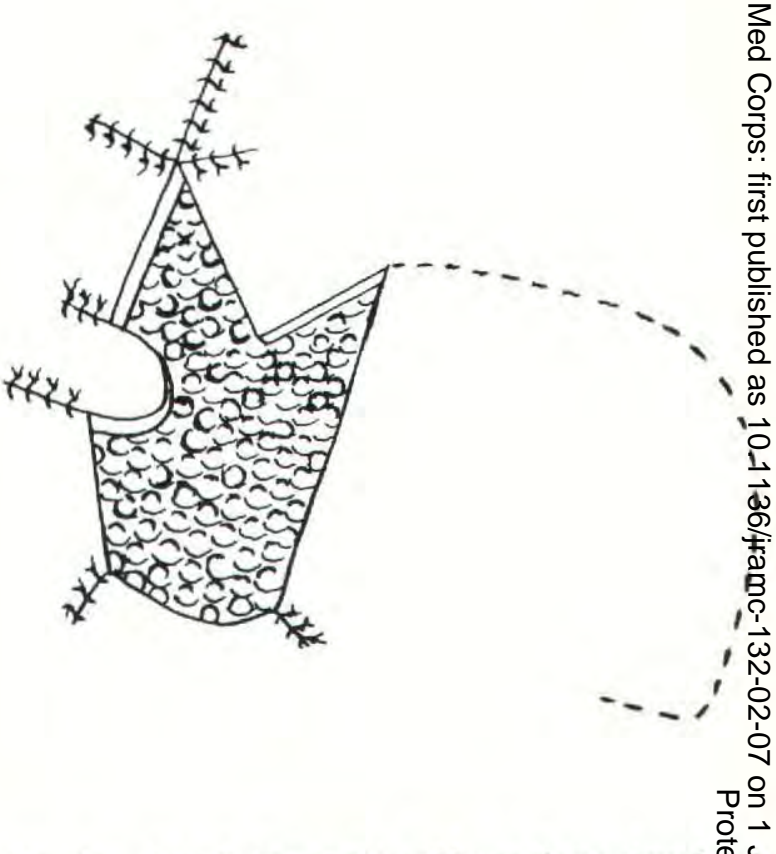

Fig.2B. Case 2. The peripheral lacerations sutured the flap designed.

㐫

б $\vec{\varphi}$

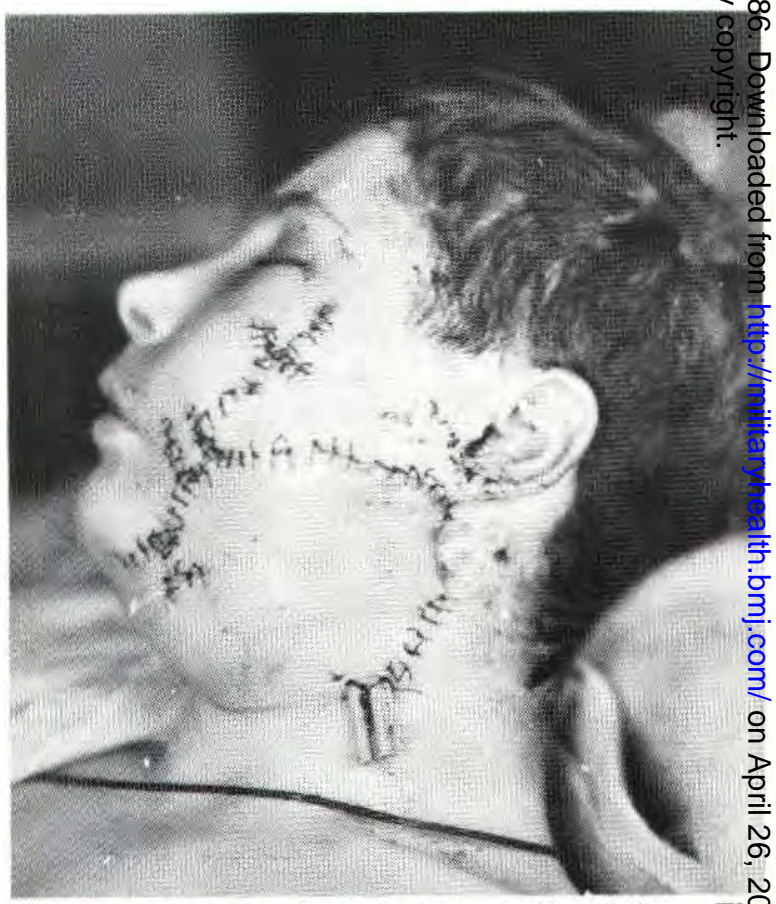

Fig.2D Case 2. Immediately postoperative. Thi secondary defect below the ear could not be closeff completely and a split skin graft was later applied. 


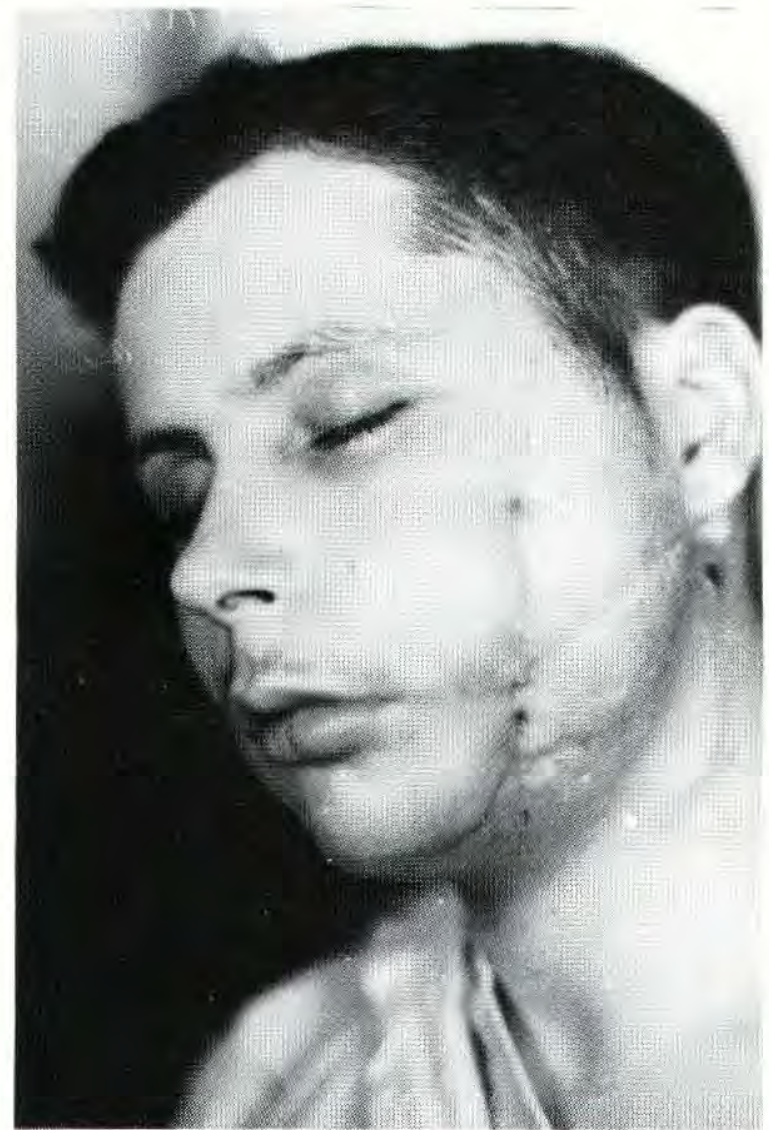

Fig.2E Case 2. Result after three weeks. Healing is complete except for two small areas where the tips of the triangular flaps met.

All stitches were removed on the fourth or fifth day, usually half of them on the fourth day and the remainder on the fifth. Where the wound had been stitched under some tension, or where the suture line was in a highly mobile site like the angle of the mouth, stitches were left in until the sixth day.

\section{Illustrative Cases}

The surgeon who first treats a maxillo-facial case has a unique opportunity. Seeing the tissues before they have become distorted and displaced by scarring, he can ascertain to a nicety the amount of loss which has occurred. From his assessment of the loss, he can then decide whether direct closure is possible, whether the loss may be made good at the initial operation by using a local flap, or whether some temporary method of closure must be used, and the complete repair left till later.

In practically every gunshot wound of the face some degree of soft tissue loss is present. The amount of loss which may still be closed directly varies in different sites and different directions. For instance, the skin of the nose is taut, and a loss greater than 2 to $3 \mathrm{~mm}$, particularly near the nostrils, cannot be sutured without distorting the alae. On the lateral surface of the cheek, however, a loss of 1 to $2 \mathrm{cms}$ can be closed with ease. Attempts to suture directly a $1 \mathrm{~cm}$ loss in a wound of the lower lip, parallel to the lip margin, will result in eversion or distortion of the lip. A similar loss in a vertical wound may be stitched without trouble. The eyelids, too, show differences. The upper is provided with an excess of skin. The lower has little, and even a small loss may result in ectropion. Each wound must therefore be assessed individually whether direct closure is possible or not. In some cases, the decision is easily made before operation; in others, it is impossible to do so until the wound has been cleaned and excised, and the result of direct closure tried.

\section{Direct Closure}

Case 1 (Fig. 1). The amount of tissue loss in this patient is probably about the limit which can be closed directly. In addition to the routine excision and suture, the remaining mandible was fixed to the maxilla with eyelet wiring and the cavity in the base of the tongue, which had been filled with loose bone, was drained through a submandibular incision.

At no time was there any evidence of sepsis. He was evacuated on the fifth day.

\section{Closure by Local Flaps}

Before deciding upon and designing a local flap, allo peripheral lacerations (and there are often many) must be excised and sutured. In addition, it must be possible to close directly any wounds of mucosa or muscle.

The design of the flap must be such as not to interfere with any later plastic procedure which may be required. In other words, local flaps should only be used when it appears possible to carry out a complete primary repair.

The flaps used were chiefly of the rotation variety, although there were a few pedicled flaps. As a rule, the secondary defect was so placed, that it was possible to obtain closure by means of tension sutures. Where this was not possible, it was covered with a split skin graft.

Complete closure by local flaps, however ideal, is a lengthy procedure and may not be justifiable if the patient's general condition is poor, nor was it possible at times when pressure of work was greatest.

Case 2 (Fig. 2). The patient was wounded by a large mortar splinter and operation was performed two days later. Much of the left body of the mandible was shattered and there was a $7.5 \mathrm{~cm}$ tear in the buccal mucosa. It was possible to suture the mucosa and the torn muscle directly and closure by a local rotation flap seemed appropriate. This was designed and transferred as shown in the illustrations. Intermaxillary fixation was applied to splint the remaining mandible.

The operation occupied four hours and two pints of blood were administered during that time. 


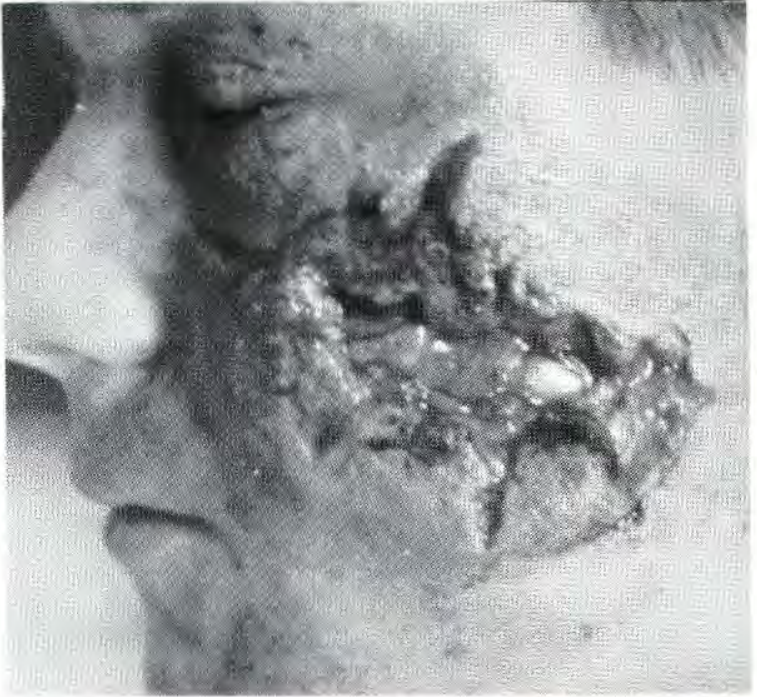

Fig.3A Case 3. Wound said to have been caused by a "bazooka" 30 hours previously.

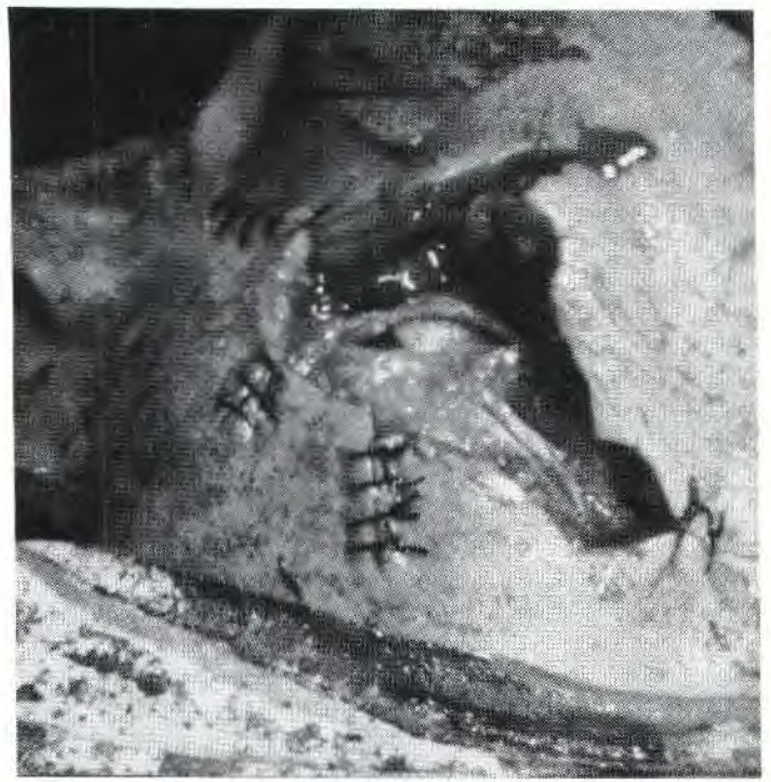

Fig.3C Case 3. After excision the fracture has been fixed with an interosseous wire (not shown) and the peripheral lacerations closed.

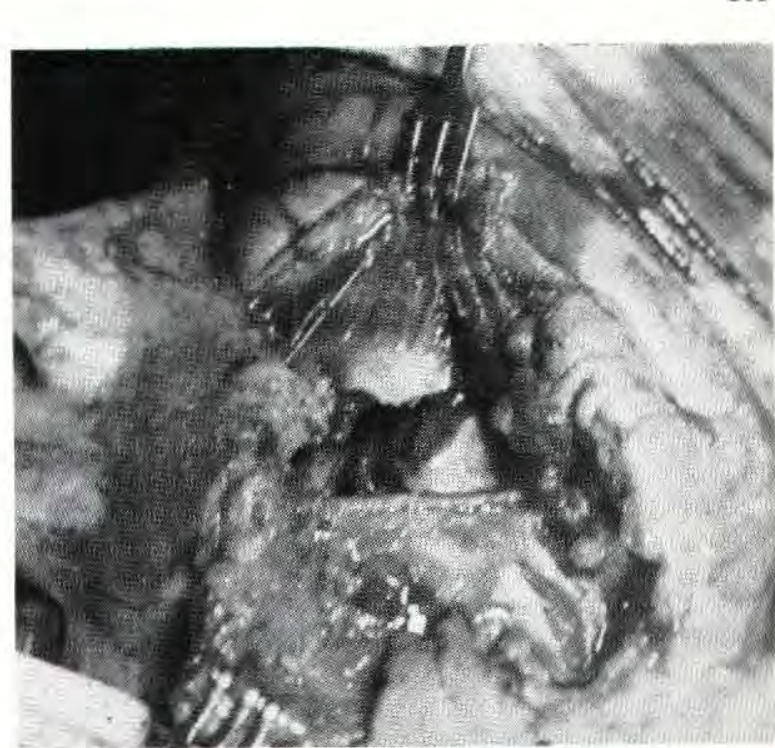

Fig.3B Case 3. Underlying fractured malar.

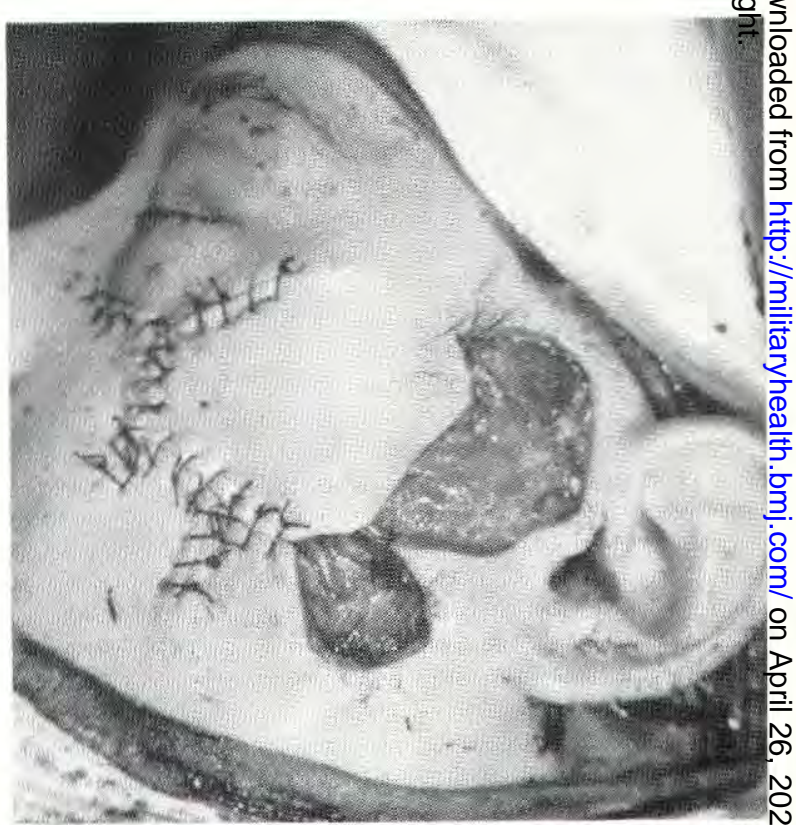

Fig.3D Case 3. Rotation flap similar in design to that in Case 2 swung into defect. 


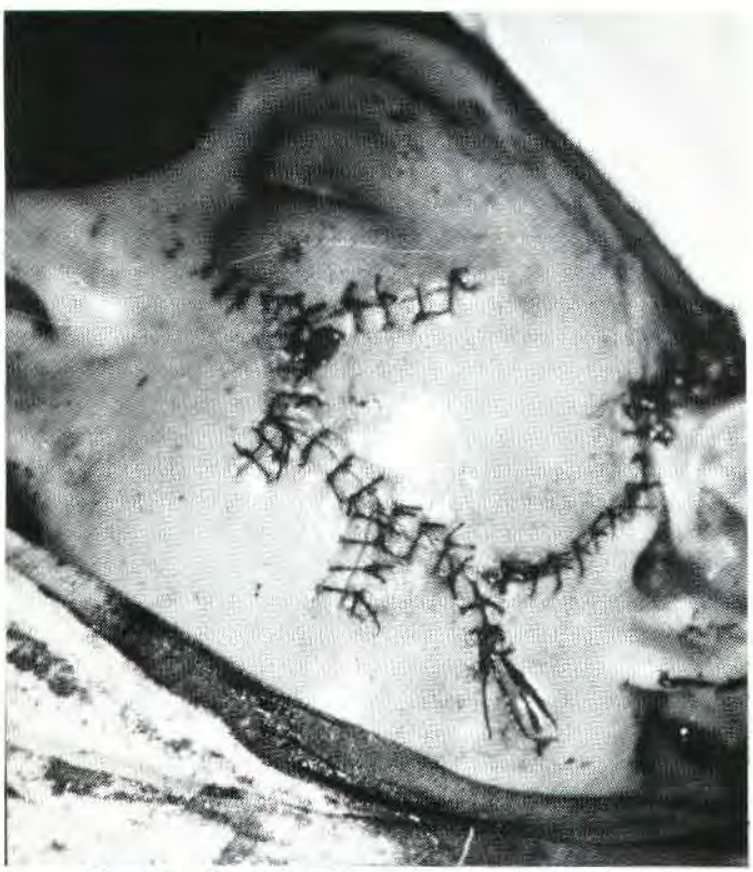

Fig.3E Case 3. The secondary defect closed.

Slight breakdown of the wound occurred after the stitches had been removed on the fourth and fifth days at sites where breakdown has been noted in other similar wounds, where the apices of several small triangular flaps met. The patient was evacuated to the UK after three weeks.

Case 3 (Fig. 3) came to operation about 30 hours after having received a wound from a "bazooka". There was a large ragged laceration on the left cheek, with obvious tissue loss, and a compound fracture of the left malar. The parotid gland was damaged in the posterior part of the wound, and a branch of the facial nerve exposed in the depths.

After complete excision of the wound, the fracture surfaces of the malar were cleaned and coapted with an interosseous wire of stainless steel. The peripheral lacerations were then sutured and a small rotation flap, base upwards, was cut and swung into place. The secondary defect in front of the ear was closed with slight tension and a drain inserted at the most dependent point.

The drain was removed after 24 hours and the stitches on the fourth and fifth days. Healing was uneventful, but saliva continued to drip from the drainage opening, apparently from the damaged parotid. He was evacuated to the UK on the 13th day.

Case 4 (Fig. 4) was admitted 36 hours after injury. The soft tissues over the right forehead were grossly lacerated and much was missing. The right eye was disorganised. The supra-orbital part of the frontal bone,

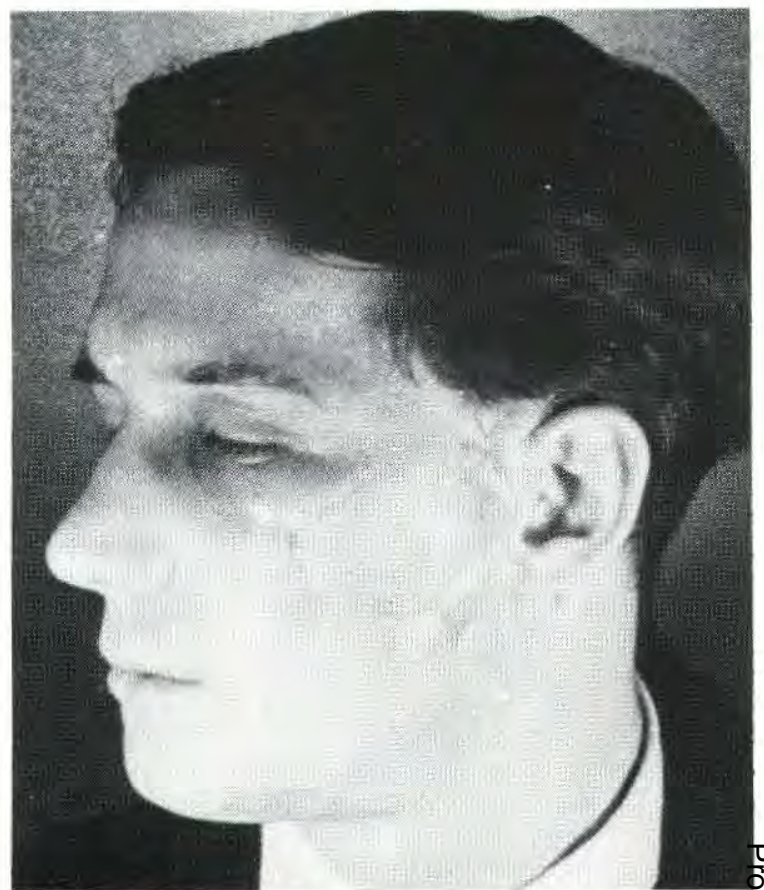

Fig. 3F Case 3. The healed result after 10 days. the orbital walls, the upper part of the right maxilla ando the right malar were grossly comminuted. Cerebrospinal fluid was leaking from the wound.

西

Operation was carried out in co-operation with Majo J N Small, RAMC, of a neurosurgical unit. The woun was completely excised, and all comminuted bone removed. The dura was exposed, and a tear about one inch long found in relation to the ethmoid air cells and the cribriform plate. Lacerated brain was removed via this tear and the tear closed with a compressed piece of Fibrin Foam.

A large flap was cut from the adjacent scalp and rotated downwards to close the defect. The remnants of the eyelids were restored to their normal position, and the conjunctival remnants carefully sutured to form a future eye socket. The secondary defect on the skull was covered with a thin split skin graft cut from the left thigh.

$\mathrm{He}$ was evacuated to the UK on the fifth postoperative day.

\section{Skin to Mucous Membrane Suture}

This method, so strongly advocated by Gillies and others since the last war, has been found very valuable in wounds involving the mouth, nose or eyelids. However, the same meticulous care in cleansing and excising the wound, in getting rid of all necrotic and contaminant material is essential, if it is to be successful. In addition, the most careful after-treatment as described above is necessary. 


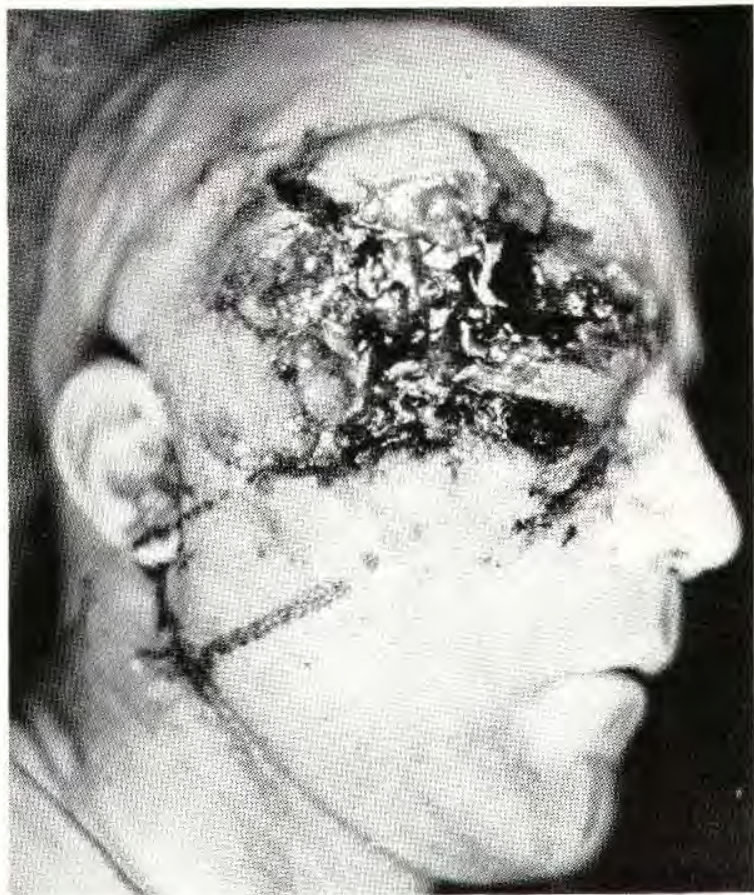

Fig.4A Case 4. A loss of soft tissues, comminuted bone, exposed dura and leaking cerebro-spinal fluid made it essential to use a flap to cover this defect.

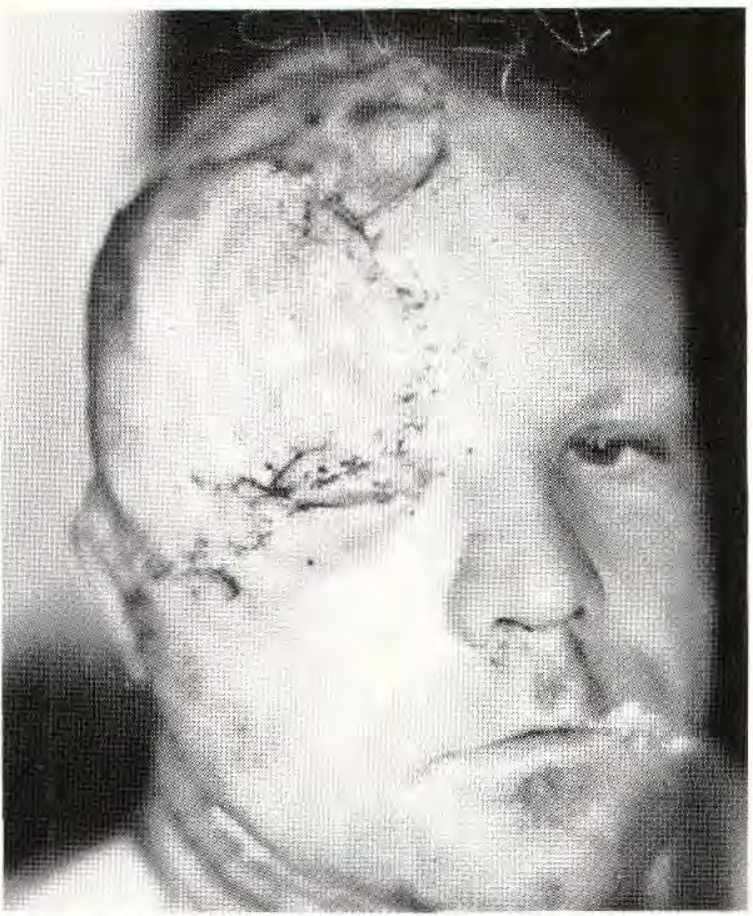

Case 5 (Fig. 5) was first seen three days after injury. The only prior treatment had been a tracheotomy. The wound was very dirty and covered with sloughs. There $\mathbb{D}$ was a loss of soft tissue involving the right two-thirds of the lower lip and a considerable portion of the right side 응 of the chin. The wound on the right side ran back to the angle of the mandible. The whole central portion of the $\overrightarrow{\vec{F}}$ mandible was destroyed.

In spite of the time which had elapsed since injury, and the dirty condition of the wound, the usual technique was followed. All loose debris was $\frac{\bar{s}}{\sqrt{Q}}$ removed and the wound completely excised. The $\stackrel{\mathbb{Q}}{\mathscr{Q}}$ peripheral lacerations were then sutured directly, and the remaining defect closed by stitching skin to themucous membrane of the lip, cheek and floor of the? mouth.Care was taken to see that the mandibular $\overrightarrow{\vec{\omega}}$ stumps were properly covered before fixing them to the maxilla with eyelet wiring.

The wound cavity was drained through a separate submandibular incision.

He was evacuated to the UK on the fifth post- $\vec{\omega}$ operative day.

Case 6 (Fig. 6). There was a complete loss of all soft $\hat{o}^{1}$ tissues of the lower lip, chin and submandibular region, down to the upper level of the thyroid cartilage. TRe greater part of the mandibular body was blown away afod numerous fragments of bone and teeth were deepogs driven into the base of the tongue and the adjacesto

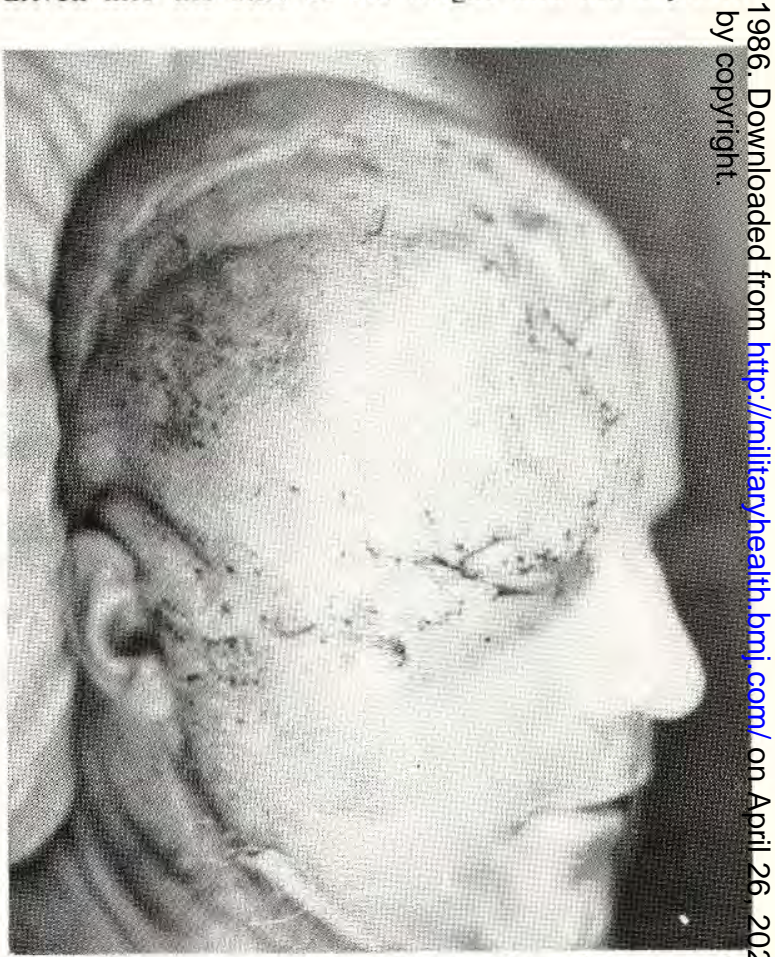

Figs 4B \& C Case 4. The operation was carried out in association with a neurosurgeon. After excision of the wound aw scalp flap was rotated into the defect and a split skin graft was used to cover the secondary defect. 


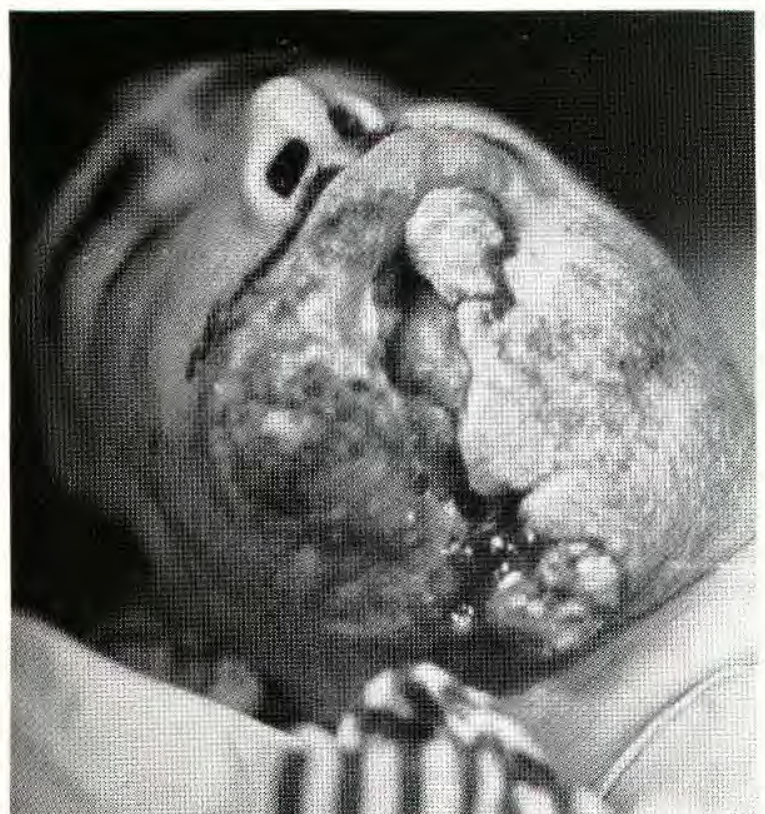

Fig.5A Case 5. Three day old gunshot wound with tissue loss of lower lip, right side of chin and a grossly comminuted fracture of the central mandible. All the raw areas were covered in sloughs.

tissues. The maxillary alveolus was shattered and splayed out, and the palate was torn. The left antrum was opened up, but the main maxillary block was firm.

He was admitted 20 hours after injury with a very rapid pulse and in distress. The wound was still bleeding. In addition to other resuscitation measures, two pints of blood and four pints of plasma were given during the next 12 hours with marked improvement. Operation was then carried out.

The wound was treated sectionally, each section being cleaned, excised and sutured before proceeding to the next. The maxilla was first dealt with. All loose detached pieces of alveolus and all roots of broken teeth were removed, and the mucous membrane carefully sutured to cover the exposed bone. One larger piece of alveolus, which still had a soft tissue attachment, was wired in position to the main maxillary block.

The cheeks were closed by first stitching all peripheral lacerations, and then suturing skin to mucous membrane around the remaining defect. The under surface of the tongue, and the large raw area on the upper neck, were completely excised and care was taken to remove all pieces of loose bone and tooth fragments imbedded in the root of the tongue. Closure was effected by first approximating the skin in the midline of the neck as far as possible and then stitching the remaining skin edge to the mucous membrane of the tongue and floor of the mouth. This had the advantage of pulling the tongue

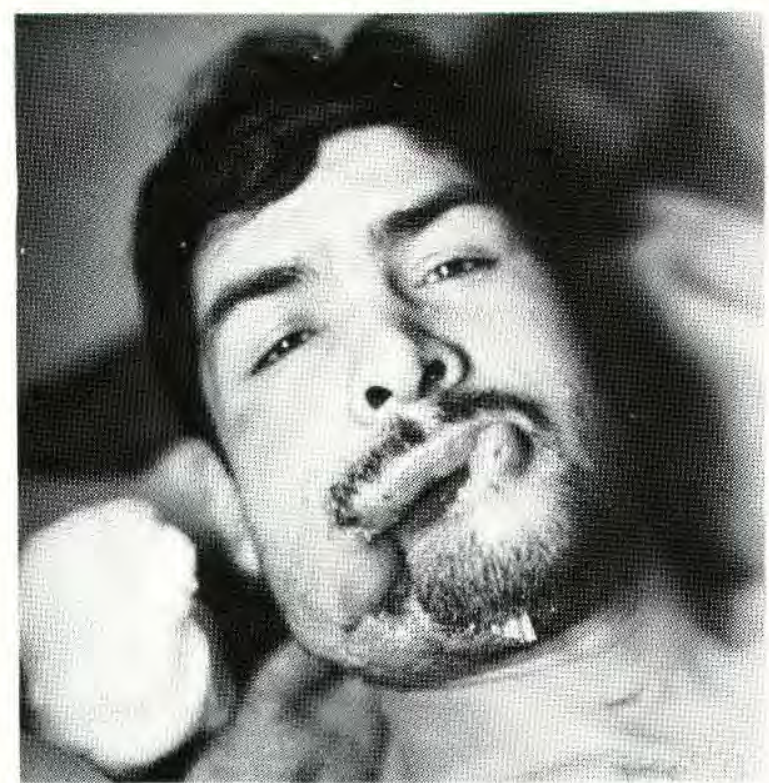

Fig.5B Case 5. Healed result on the fourth day after removal of stitches. The completely excised wound has been closed by stitching skin to mucosa around the defect ${ }^{-}$ The drain was left in longer than usual because of the original dirty conditions. No sepsis developed.

somewhat downwards and forwards since the anterior fixation of the tongue had been lost.

The mucous membrane of what remained of the floo of the mouth was closed, adequate covering of the mandibular stumps being achieved. No attempt was? made to fix these in this case.

Three drains were inserted; one to the region of each mandibular stump, and one to the cavity in the base of the tongue.

Tracheotomy was performed at the end of the operation and a small bore tube passed into the stomach for feeding purposes. The operation lasted just over three hours during which time two pints of blood were given. A pint of plasma was administered postoperatively.

The post-operative period was uneventful.The drains were removed after 24 hours, and half the stitches on the fourth day. No sepsis of any kind developed. He was evacuated to the UK on the same day.

Comment. Figs. 5 and 6 illustrate well the usefulness of muco-cutaneous suture. The improvement in general condition, the lack of discomfort and the uplift in morale were always dramatic, when it was carried out in extensive injurics such as those shown. Case 6 is an example of one of the most severe maxillo-facial injuries to reach hospital. The value of obtaining primary epithelial covering for such a case cannot bc overestimated. The future of such a patient if healing were allowed to proceed by granulation is unthinkable. 


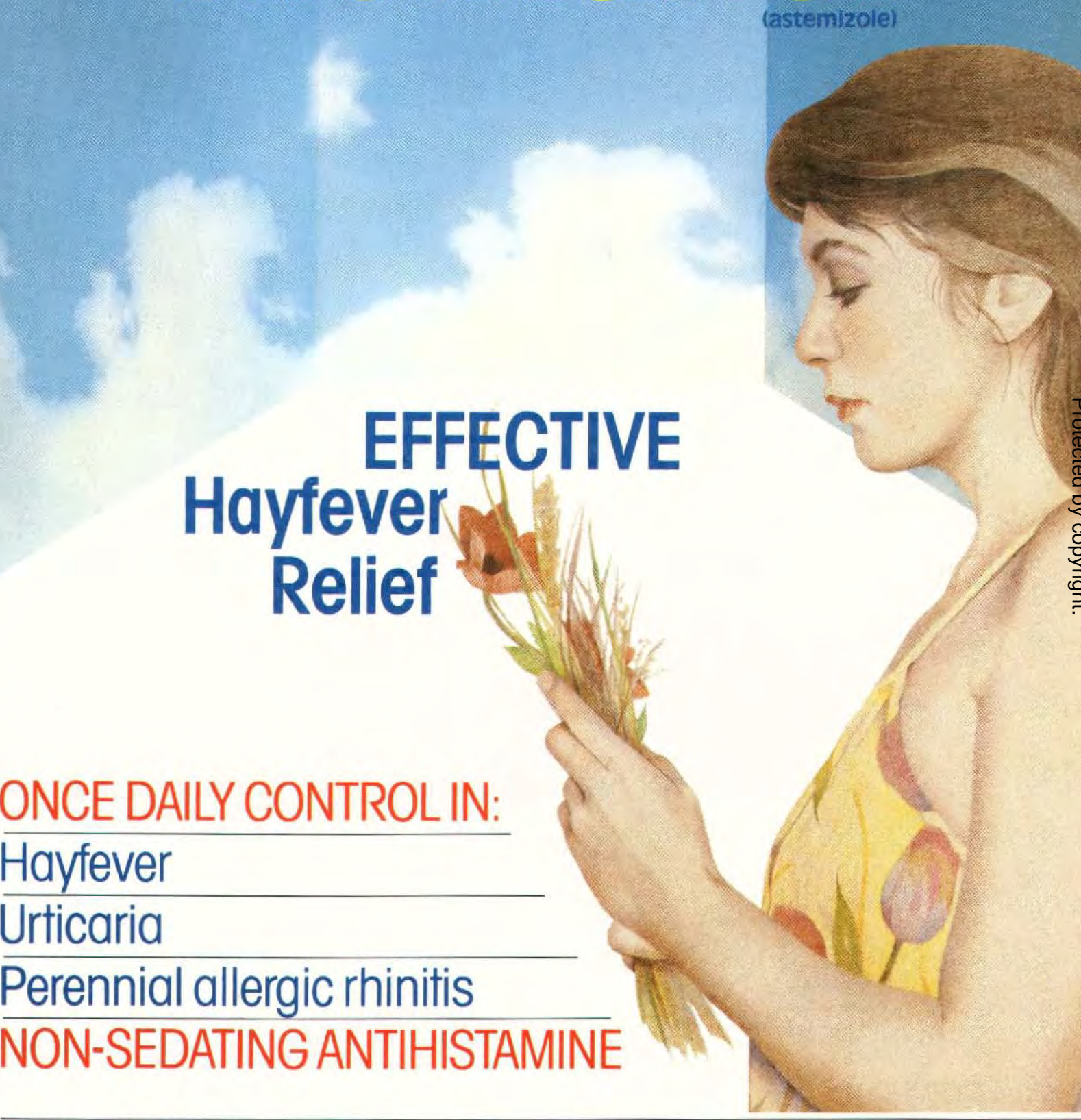

Prescribing Information USES: Hismanal* is a non-sedative antihistamine indicated for allergic rhinifis and conjunctivitis and other conditions normally responsive to antihistamines, including allergic skin reactions (urticaria). DOSAGE AND ADMINISTRATION: To be taken on an empty stomach. Adults and Children over 12 years: Usually $10 \mathrm{mg}$ daily When necessary up to $30 \mathrm{mg}$ once daily may be given for up to 7 days, then $10 \mathrm{mg}$ daily Children 6-12 years: Half the adult dose. CONTRA-INDICATIONS ETC. Contra-indicated in pregnancy PRECAUTIONS: Like many other antihistamines, Hismanal* has been associated with adverse effects on the maintenance of pregnancy in rats, and adequate contraceptive precautions should be taken in women of childbearing
Generally infrequent: weight gain has been reported. No known interaction with CNS-depressant drugs including alcohol. Does not interfere with activities requiring mental alertness, for example, driving or operating machinery. OVERDOSAGE: Supportive measures or gastric lavage as necessary PRESENTATION: White, biconvex, half scored, uncoated tablets morked 'Janssen' on one side and Ast/10 on the reverse. Each contains astemizole $10 \mathrm{mg}$ : supplied in packs of 30 tablets. LEGAL CATEGORY: POM. PRODUCT LICENCE NO.: PL 0242/0086. BASIC NHS COST: Pock of 30 tablets: $£ 4.95$ further information is available on request from: 

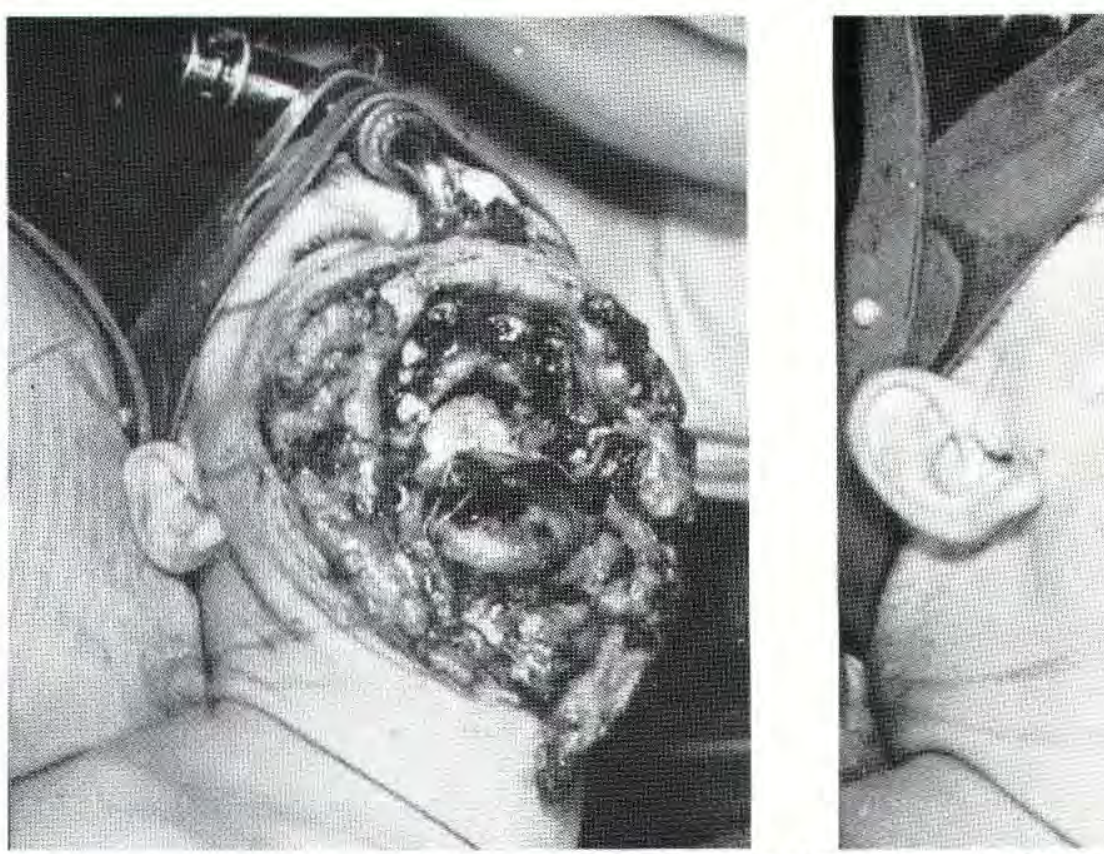

Fig.6A \& B Case 6. Severe "blow out" injury of the lower face with a loss of lower lip, chin, most of the mandible and fractured maxilla. For details see text.
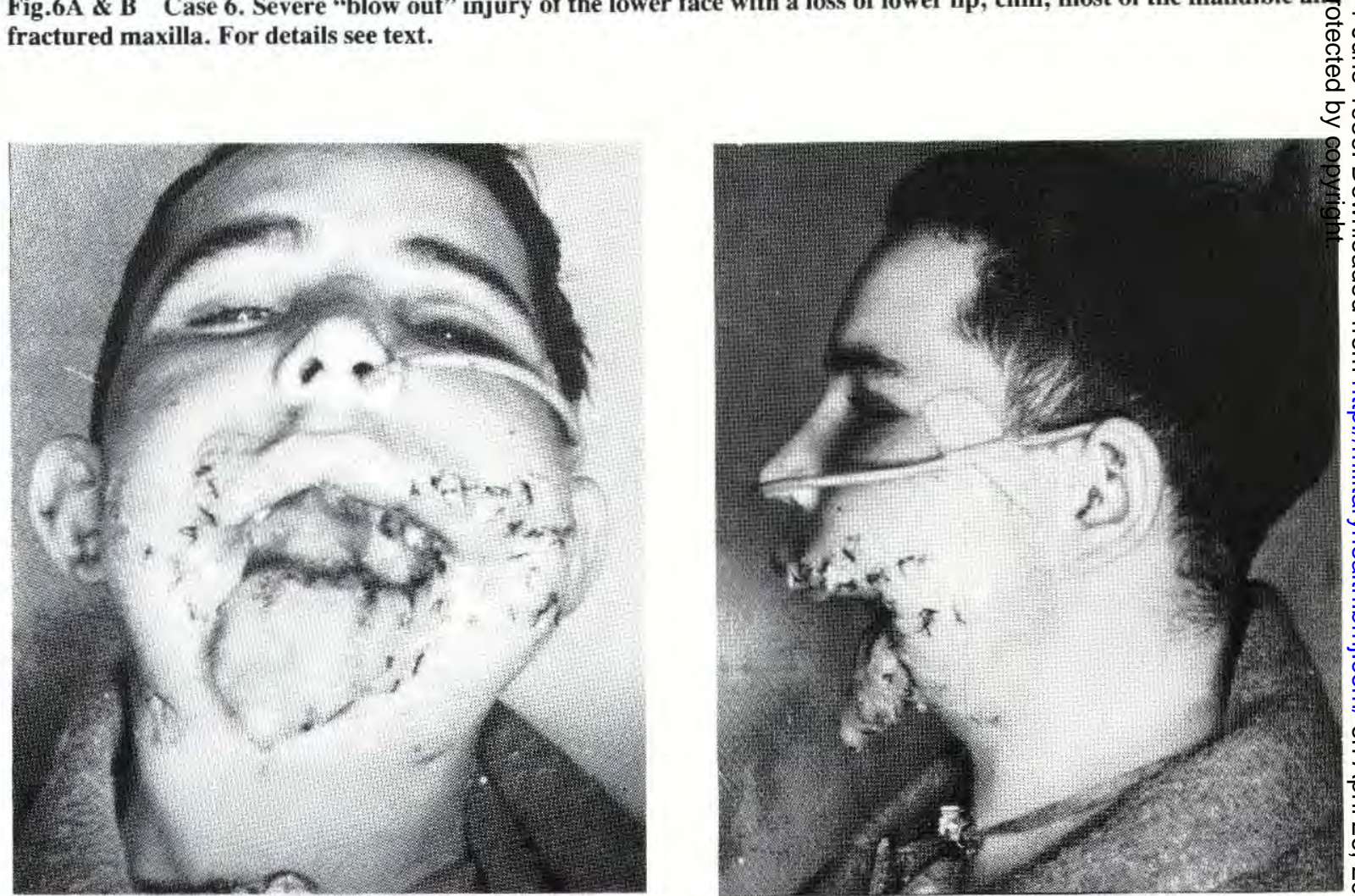

Fig.6C \& D Case 6. Healed result on the fourth day after removal of some stitches. Complete epithelial cover has been $\omega$ obtained by muco-cutaneous suture. For details see text. 


\section{Split Skin Graft Closure}

This method was found to have a much more limited application than was at first expected. There were two main difficulties. The first was in securing absolute haemostasis of the raw surface, without burying too much catgut. This could be done, but it took time, and time could seldom be spared. The second was to obtain adequate pressure on the graft. This also could have been achieved, if one had known about the case 24 hours in advance, and obtained the services of the dental department to make the necessary appliances; but this was never possible.

In the cases in which the method was used, pressure was obtained by means of a pad of flavine wool, held in position by the ends of the stitches used to fix the graft to its bed.

Case 7 (Fig. 7). A free split skin graft was used to effect primary closure in this very extensive wound. First seen two days after injury, the wound involved the oral cavity and the mandible was comminuted from $\overline{4}$ to the angle.

\section{The Land Mine Injury}

This was one of the commonest types of facial injury during the campaign. There was always a variable amount of soft tissue damage with widespread tattooing of small black particles into the skin. If seen early the small particles can be scrubbed out, but the small puncture wounds heal over rapidly and after a day or so it becomes increasingly difficult to remove them.

Case 8 (Fig. 8). This man had been held at a Casualty Clearing Station because of a traumatic amputation of his right foot and was not admitted until the fourth day after injury. There was a full thickness wound of the upper lip with loss of most of the philtrum. The premaxilla was exposed for about $2.5 \mathrm{~cm}$ on each side of the midline and severely contaminated with dirt. The columella and the tip of the nose were torn in shreds most of which were gangrenous. There was no evidence of sepsis.

By scrubbing the face with Cetavlon as much as possible of the imbedded debris was removed. After excision it was possible to close most of the wound directly. The columella and the lower part of the nasal septum were a total loss and by trimming back a little of the septal cartilage it was possible to suture the mucous membrane on each side across the defect.

\section{Results}

It is extremely doubtful if a final assessment of the results in these cases will ever be possible.Evacuated to England, as most of them were shortly after operation, and distributed to many centres, they will be almost impossible to trace. In an attempt to surmount this difficulty, stamped addressed follow-up postcards, asking for information on later progress, have been inserted with the papers of every patient evacuated. Although some units have been most helpful, the return

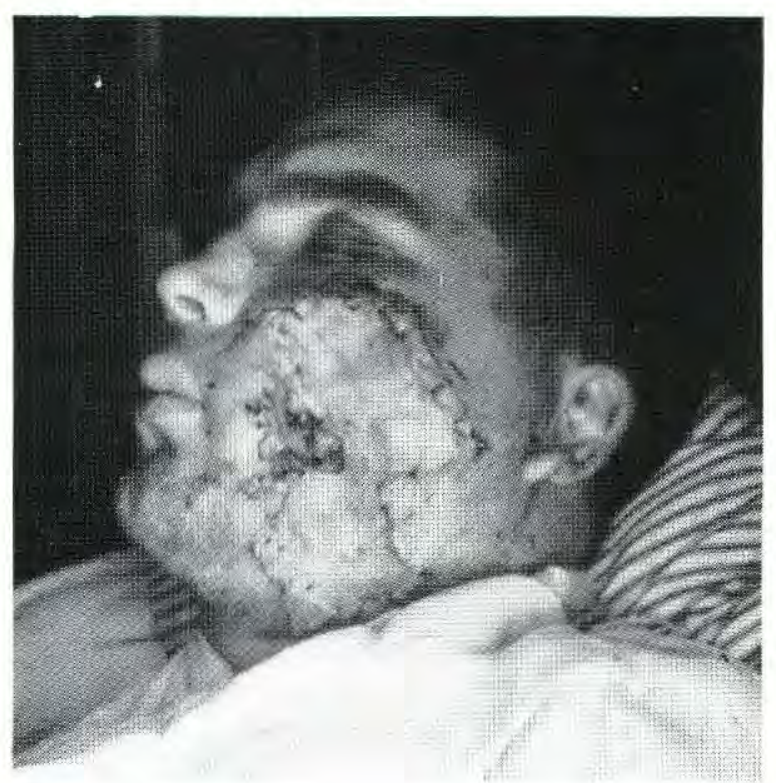

Fig.7 Case 7. This extensive wound with loss of soft tissues, torn buccal mucosa and a shattered mandible was excised and split skin grafted three days before thi photograph was taken. The buccal cavity remaineod exposed and, anteriorly, skin had been sutured t mucosa. He was evacuated on the same day to the UK $\vec{\sigma}$ and at the time most of the graft was vascularised and there appeared to be a 100 per cent take.

has been very disappointing, and only a small proportion of the cards have been received.

However, it was our policy to retain cases, where circumstances permitted, for at least five or six days until all stitches had been removed. Many cases, as will be evident from the illustrations, were retained even longer. It is therefore possible to obtain much :nformation about, and a fairly accurate picture of, the immediate results of primary closure. Of the late results, such as sepsis, scars and keloids, very little is known.

Six deaths occurred in the series, a mortality rate of 2 per cent; in two cases, death was directly related to the facial wound; in three it was due to associated injuries; in one the cause of death was not discovered.

In the wounds themselves, sepsis was so rare as to be practically non-existent. Stitch abscesses or cellulitis were never seen. When sepsis did occur, it was deep seated and associated with retained debris in the tissues. In one or two of the very early cases in whom excision of the deep wound was incomplete, follow-up notes received from the UK described the skin wound as soundly healed, but merely acting as a roof over a pocket of pus originating from retained foreign and necrotic material. With improvements in technique, this source of infection was largely overcome. . . 
The results have been divided into three groups: successful closure in which no breakdown of the wound occurred;

partial breakdown where a small part of the wound opened after the removal of stitches;

failure where the whole or greater part of the wound burst open.

Partial breakdown nearly always occurred either where the apices of two or more small flaps met and was probably due to vascular insufficiency, or where the wound had been stitched under tension.

Of the 304 cases of primary suture in this series, 149 were evacuated before the fourth day. On these, thereforc no decision can be made, although all wounds were inspected before evacuation, and no case was evacuated if there were any signs of trouble. Only 10 follow-up cards ( 6.7 per cent) have been received for these 149 cases. Although they showed six cases of successful closure, three partial breakdowns and one failure, the numbers are far too small for any conclusions to be arrived at. Our own observed figures are probably more representative of the results as a whole.

The results in the remaining 155 cases were as follows:

Returned to unit completely healed

(average time 6 days)

Retained for 4-7 days before evacuation 69 cases

Successful closure

64 cases

Partial breakdown

5 cases

Failure

0 cases

Four follow-up cards have been received in this group. Three confirmed success; in one there was a later breakdown.

Retained for more than seven days

Successful closure

56 cases

Partial breakdown

54 cases

Failure

2 cases

0 cases

If we add together the cases retained for more than four days we have a series of 165 cases in whom the immediate results are known. These results are:

Successful closure 153 ( 93 per cent)

Partial breakdown 10 (6 per cent)

Failure 2 ( 1 per cent)

Major G.M. Fitzgibbon, OC the Unit, has kindly given me permission to state that his results in a similar series of cases, similarly treated, have been almost precisely the same.

\section{Effect of the Interval between Injury and Operation on Results}

Analysis of the results shows no difference between cases operated on the first day, and those done later, with this proviso: in a number of cases seen from the third day onwards, which were very dirty, and in whom frank wound sepsis was present, no attempt was made at primary closure. At the same time, the absence of wound sepsis in most late cases was noteworthy (e.g. Case 8 ), and was almost certainly due to the chemotherapy such patients had received. By contrast, the wounds of German POW's, which were usually seen three or more days after injury, were almost always $z$ septic; none of them had received penicillin in any $\underset{\mathbb{Q}}{\mathbb{\Phi}}$ quantity.

\section{Conclusions}

From the results given, it will be seen that primary $\frac{0}{0}$ closure of facial wounds, far from being hazardous, is an $\frac{\bar{\sigma}}{\sigma}$ eminently successful procedure. The results have $\frac{\bar{\sigma}}{\bar{\sigma}}$ probably been due to several factors: a specialist unit as $\widetilde{\Phi}$ far forward as possible so that cases were seen early; the $\frac{\Omega}{\Omega}$ most meticulous wound toilet including complete $\Phi$ excision of the wound; the routine use of penicillin and $\overrightarrow{0}$ the sulphonamide drugs.

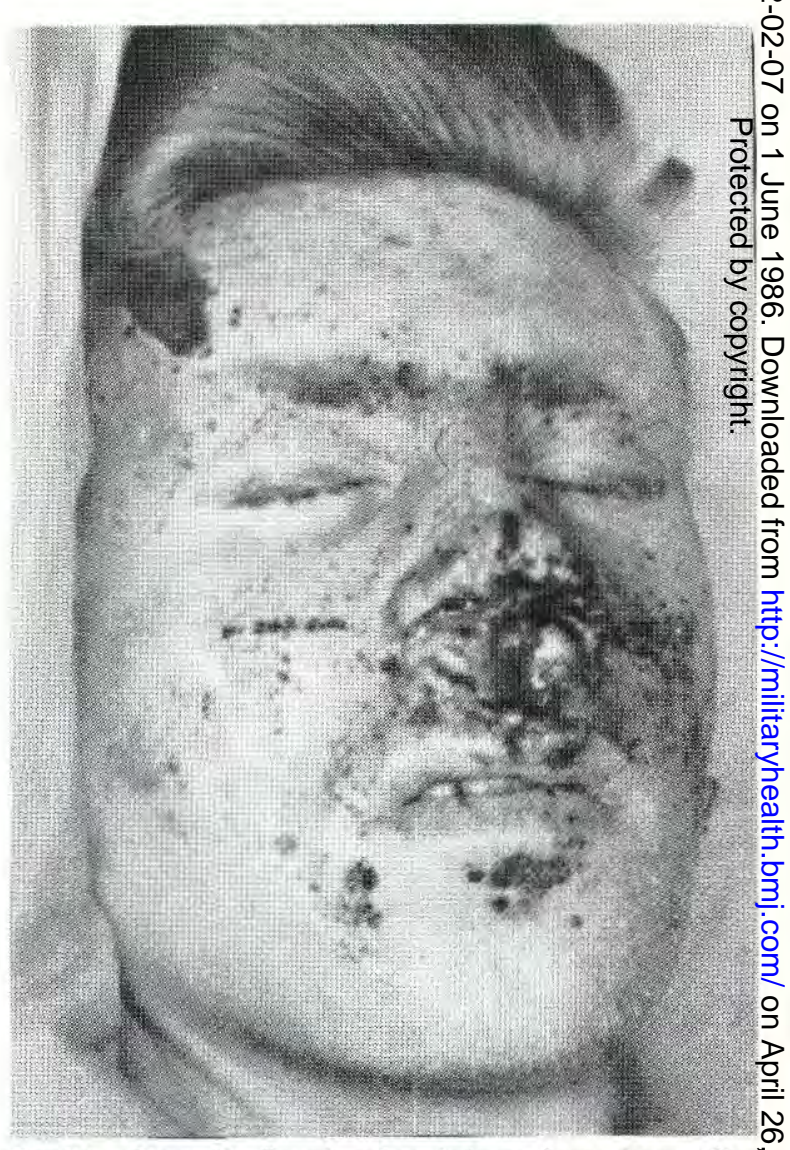

Fig.8 A Case 8. Land mine injury four days after wounding. In addition to the lacerations of the upper lip and lower nose, many tiny particles were imbedded in the face. 

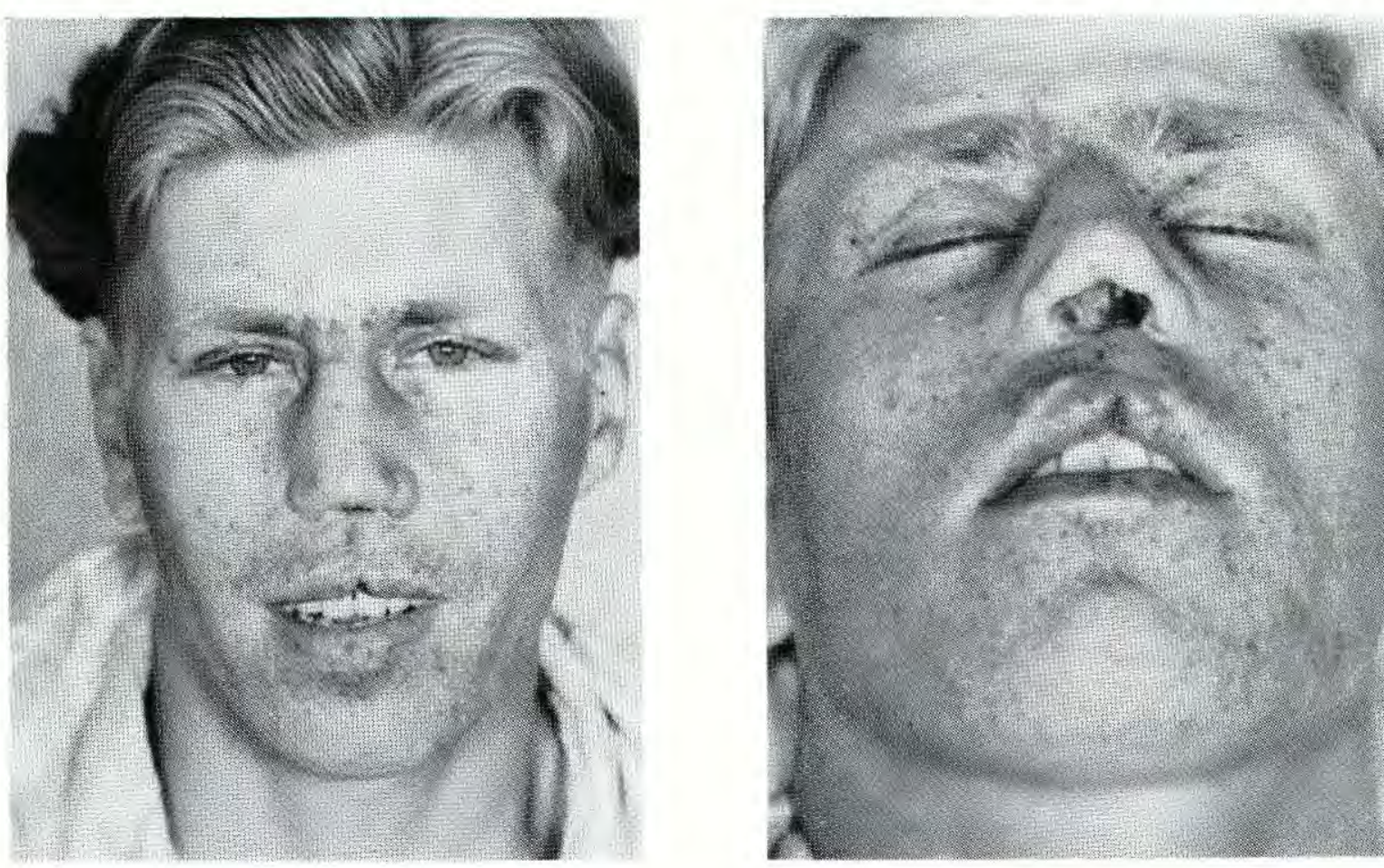

D

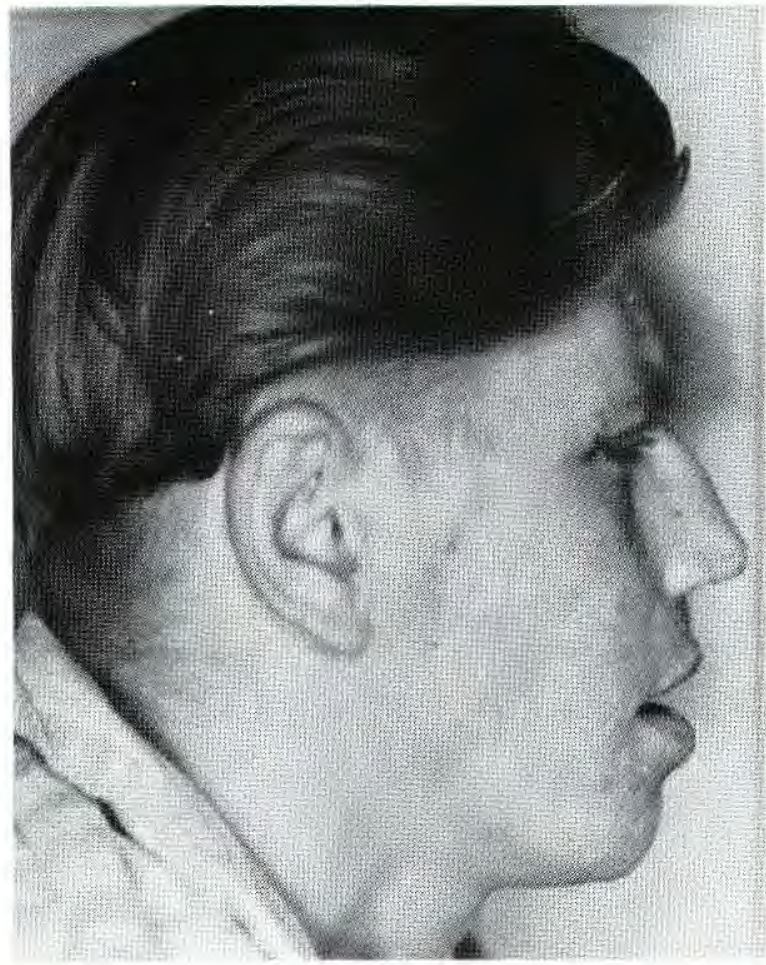

Figs.8B, C \& D Case 8. The healed result 17 days after $\stackrel{\mathbb{Q}}{2}$ operation. The lost philtrum has been closed directly by $\overrightarrow{\vec{O}}$ interdigitating small flaps from each side. The lost 3 columella has been covered with mucosa from each side after trimming back the septal cartilage. There is still some residual tattooing. (These three figures were kindly supplied by RAF Hospital, Wroughton.) 


\section{Acknowledgements}

My most grateful thanks are due to the following: Major G M Fitzgibbon, RAMC, OC the Unit, not only for his permission to carry out the work and publish the paper,but also for his never failing enthusiasm, encouragement and advice; Majors N W A Holland, L M Irwin and J C F Rolls, AD Corps, who have been responsible for the treatment and fixation of the jaw fractures; Majors H L Thornton and E G Godwin, RAMC, anaesthetists to the Unit.

I wish also to acknowledge my indebtedness to Sir $\mathrm{H} D$ Gillies and his co-pioneers in plastic surgery for the fundamental principles on which this work is based.

\section{REFERENCES}

1. Gillies H D. Plastic Surgery of the Face, Oxfo University Press, 1920.

2. OLDFIELD M. Some experience of reparative surgery 8 the Middle East; with a short review of 1200 cases treate during the last two years. Brit J Surg 1944; 32: 237-245. ?.

3. A Field SuRgery PoCKet BOOK. The War Office 194 21: 135 .

\section{SERVICE SPECIALIST'S SPINAL INJURY RESEARCH}

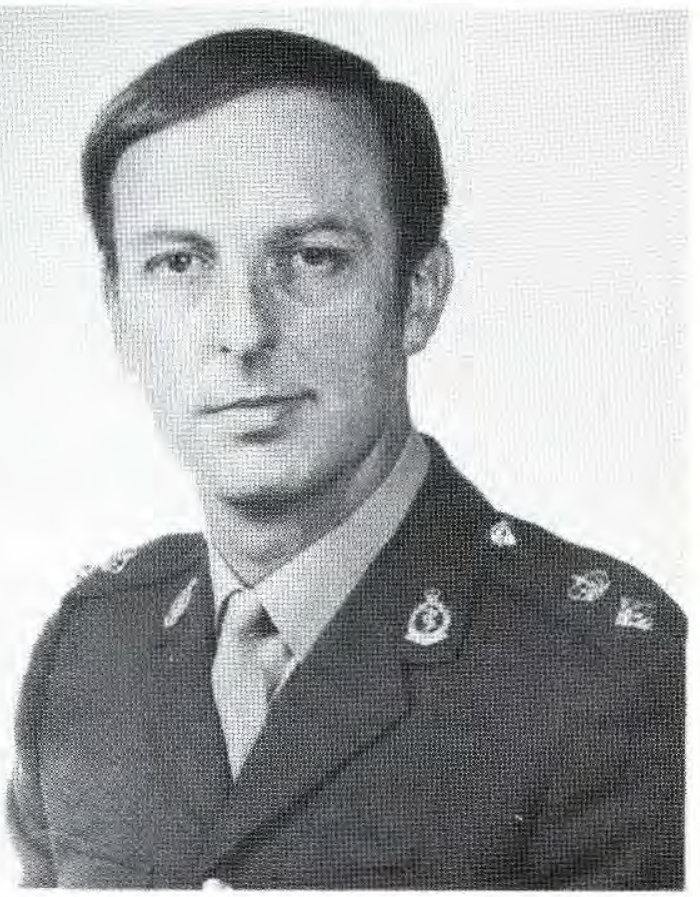

The Smith and Nephew Foundation's Service Doctor Award for 1986 has been given to Lt Col Robin Garnett, Consultant in Rheumatology and Rehabilitation at Queen Elizabeth Military Hospital, London. He receives a grant of $£ 4,000$ and will use it to visit hospitals in Miami, Boston, Dayton, Cleveland, Hamilton, Denver, New Orleans, Phoenix, San Jose and Los Angeles in the United States and in Perth, Melbourne and Sydney in Australia between May and August of this year.
Col Garnett will study major developments and nei procedures in the treatment of rehabilitation of spinol injury patients in the United States where some of the research and practice in Specialist Centres is in advanice of that in Britain. He believes that within 20 years the new methods could lead to a reduction of at least $50 \stackrel{\circ}{\mathrm{D}}$ the numbers of patients confined to wheelchairs.

$\mathrm{He}$ will also visit Professor Harry Goldsı̊fiक (Professor of Surgery at Boston University Hospita renew his interest into omental transpositione. revascularise the spinal cord. He first met Profe Goldsmith in Britain during a liaison visit with $\mathrm{Mr}$ of Neil-Dwyer, Consultant Neurosurgeon to the Soug East Regional Neurosurgical Centre in London whe this technique is being pioneered in Britain.

In his present appointment Col Garnett is Head of the Rheumatology and Rehabilitation Department in twe Army's main referral hospital. There is a close link wi the South East Regional Neurosurgical Unit for tt rehabilitation of many of the Army hospital's long ter patients, of whom about half are now civilians. He als has an honorary appointment in Electromyography $\mathbb{G}_{\mathrm{t}}$ St Thomas' Hospital, London. His publications inclucte several papers on the physiology of human sping reflexes.

The Smith and Nephew Foundation was establisheê in 1974 by Smith and Nephew Associated Companies Limited to channel all the company's corporaf charitable donations into medical education an

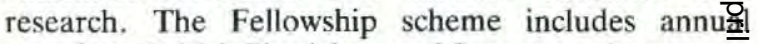
awards to British Physicians and Surgeons who want to undertake a year's research project overseas, an annual Fellowship in Sports Medicine to enable the holder undertake a Diploma Course in the subject and $\mathbf{N}^{\circ}$ Fellowship in Ophthalmology at Moorfields E Hospital. 